\title{
The Study of "Xiaolun" in the Interaction Role Between Confucianism and Buddhism and the Buddhist Filial Piety
}

\author{
Wu Bin \\ History and Culture Department, Central China Normal University, Wuhan, China
}

\section{Email address:}

history307@163.com

\section{To cite this article:}

Wu Bin. The study of "Xiaolun" in the Interaction Role Between Confucianism and Buddhism and the Buddhist Filial Piety. Science Innovation. Vol. 5, No. 3, 2017, pp. 127-131. doi: 10.11648/j.si.20170503.11

Received: April 2, 2017; Accepted: April 13, 2017; Published: April 20, 2017

\begin{abstract}
The Confucian society advocate "filial", and some rules and precepts of Buddhism Confucianism between draw further apart, so the contradictions and conflicts, so in this situation, how to re interpret the connotation of filial piety culture, adapt to the different periods of Buddhism two teach, has become an important issue in ancient China the ethics of society. As Confucianism teaches communication under the two product of the Northern Song Dynasty, "Xiaolun" is one of the two teaching media through communication and dialogue, Qisong's filial piety, explore the traditional culture of filial piety in Confucianism interaction, how to promote Confucianism and Buddhism complete absorption and transformation each other in interactive communication, and pointed out that Buddhism The extension of Confucianism is the essence of the Buddhist filial piety.
\end{abstract}

Keywords: Xiaolun, Filial Piety Culture, Interaction Between Confucianism and Buddhism, Medium, The Buddhist Filial Piety

\section{《孝论》在儒释互动中的媒介作用与佛教孝道化的研究}

吴玢

历史文化学院, 华中师范大学, 武汉, 中国

邮箱

hitory307@163. com

摘要：儒家社会提倡 “以孝治天下”，而佛教的一些戒规戒律却与之背道而驰，这样儒释之间就产生了矛盾和冲突， 因此在这一困境下, 如何重新解读孝文化的内涵, 适应不同时期的儒释二教, 就成为中国古代伦理社会的一个重要课 题。作为儒释二教沟通对话下的产物, 北宋契嵪的《孝论》就成为儒释二教沟通对话的媒介之一, 透过契嵪的孝道观, 探讨传统孝文化在儒释互动中的作用, 如何促进儒学与佛教在互动沟通中完成了彼此的吸收和改造, 并指出佛教儒学 化的外延的本质就是佛教孝道化。

关键词: 《孝论》, 孝文化, 儒释互动, 媒介, 佛教孝道化

\section{1. 引言}

孝既是中国传统道德的重要核心，也是儒家伦理思想 的重要内容。孝文化的产生正是源于远古时期的先民崇拜
和祖先敬畏, 后来孝文化的概念衍生为 “葬之以礼, 祭之 以礼” [1], 从物质和精神上尊敬父母、赡养父母。而在 儒家思想的熏陶下, 忠孝一体又成为传统社会的道德信念, 这一点曾是中华民族发展链上至关重要的一环, 对于社会 的稳定、人心的凝聚、道德行的统一等都具有强大的推动 
作用, 培养出中国古代士人强烈的忠君爱民思想, 可以说, 孝文化对于封建时代民众的道德规范和人格塑造以及社 会秩序的维护, 甚至是在宗教信仰方面的浸透也起着不可 或缺的作用。儒家社会提倡 “以孝治天下”, 主张 “天之 经也, 地之义也, 民之行也, 德之本也”（出自《孝论・原 孝章第三》, 下同）的道德准则, 而佛教的一些戒规戒律 却与之背道而驰, 这样儒释之间就产生了矛盾和冲突, 究 竟是重孝抑或是不孝, 二者的争论自从佛教传入中原地带 开始就不相上下, 本土与外来碰撞的困境长期影响着国家 社会的和谐稳定。因此在这一困境下, 儒释之间的互动显 得不可或缺, 也成为外来的佛教在中国传统儒家理念浸透 下继续生根发芽的契机，而孝文化的内涵就成为儒释二教 沟通对话的媒介, 佛教也由此在与儒家的会通中完成自我 的吸收和改造。本文以佛教史上重要的经典《孝论》为例, 分析契嵩的孝道观, 探讨传统孝文化在儒释互动过程中的 媒介作用, 从而阐释出佛教为传统社会孝道化土壤的灌溉 提供了养分, 以及对于当今道德伦理和世界观塑造的启示。

\section{2. 北宋 “排佛” 思潮的兴起}

自从佛教东渐之始, 就面临两个极端: 一方面深受中 原社会各阶层的广泛欢迎，同时另一方面又备受世俗统治 者的诟病, 特别是以主流意识形态捍卫者自居的儒家士人, 更是因佛教产生的诸多弊端而极力抨击之。这方面尤以中 唐时期的韩愈为首, 在他的带领下, 唐朝中期以降到宋朝 初年, 在社会上掀起了轰轰烈烈的 “排佛” 运动, 影响十 分深远。陶新宏先生将儒家 “排佛” 的思路方式归纳为以 下三点: “一是斥责佛教与封建伦理纲常相违; 二是斥责 佛教危害王道政治; 三是关于 “夷夏之辨”。” [2]因此, 在儒家看来, 所谓的佛教异端“无益于时政, 有损于治道”, 一点也不符合传统道德伦理的范畴, 甚至反其道而行之, 对封建社会的稳定和统治秩序的维护不仅起不到任何作 用，而且大为有害。

佛教在唐朝时得到了迅速的发展, 受众达到了鼎峰, 但是它急剧膨胀的同时, 也导致了不少滥解: 僧尼大作增 长, 良莠不齐, 加重了国家管理负担; 寺院鳞次栉比, 盲 目建造, 不利于经济正常运转; 崇佛风气日盛, 竞相论禅, 儒学渐被佛教所侵染; 财富消耗过多, 利益受损, 导致整 个社会都㿈疾。特别是唐末五代以来的分裂割据, 使得封 建社会的统治完全失序, 儒家伦理纲常也陷入混乱的局面, 因此重整社会秩序, 重建伦理纲常就成为儒家士人的迫切 愿望和共识。于是待赵匡胤黄袍加身后, 恢复儒家传统伦 理道德, 力倡儒学, 重视文臣就成为首要任务, “尊韩” 和 “排佛” 思潮愈演愈烈, 两者是同步的, 归根结底都是 为了维护儒家的 “道统” 地位。这场 “自佛老流行中国以 来最广泛持久且最深入的反宗教的思想运动” [3], 在北 宋前期进展地轰轰烈烈: 孙复认为佛教是 “以夷狄诸子之 法, 乱我圣人之教耶” [4]; 甚至欧阳修在修撰史书时, 也删减了一切与佛教有关的史实记载。“当佛教出世主义 遭到儒家的坚决抵制和猛烈抨击后, 为了生存, 也为了更 好地发展, 佛教开始由不自觉到自觉、由被动到主动对自 己的出世主张进行了调整” [5], 而一批站在儒家对立面
的佛教释人面对这种困境, 开始为佛教的发展寻求新的出 路, 在其中就有一位著名的高僧一一契嵩。

\section{3. 契嵩 “非韩” 护法与 “儒释一贯”}

契嵩 (1007-1072)，北宋仁宗、英宗时的著名僧人， 姓李, 字仲灵, 号潜子。他对佛法道义颇有研究, “经传 杂书, 靡不博究” ( 《佛祖历代通载》卷十九), 在佛教 的思想方面取得了很大的成就。特别是针对韩愈的 “辟佛 论” 所作了一系列文章, 阐述其 “非韩” 护法的言论, 并 收录于《辅教编》一书中。

北宋 “排佛” 思潮的日盛, 儒家士人以继承韩愈的思 想为己任, 极力捍卫儒家之道, 排斥佛教, 在这种情形下, 北宋的契嵩却反其道而行之, 采取规避、劝解的方式维护 自己的佛法, 即: 积极调和儒释二教的矛盾, 使其殊途同 归, 证明佛教并非 “浮屠害政”, 它同样对世人有用, 对 社会道德秩序的稳定有用。契嵩在佛教的倡导上, 并没有 抨击儒家的 “排佛” , 相反极力吹捧儒家的经典, 特别是 礼乐教化, 并主张帝王也可用佛法的教义戒规来维护统治, 甚至上书欧阳修来陈述自己的佛道, 希望为儒家士人所理 解。契嵩这种 “非韩” 护法的主张对于北宋时期儒家学术 思想的转变有很大的影响, 他敢于迎战当时最激烈的 “排 佛” 思潮, 并以一己之力通过对儒家学术的推崇为佛教寻 求生存空间, 随之影响了士人的心性, 开始主动地崇佛谈 禅, 甚至如朱喜、张载等人还具有儒表佛里的倾向。

契嵩在护法的过程中, 一个重要的主张就是提出了 “儒释一贯” , 将儒佛二教同样视为 “圣人之教” : “治 世者非儒不可也, 治出世非佛亦不可也。” [6]儒家主张 治世, 佛教主张出世, 二者之目的皆为 “各以其法赞陛下 之化治” [6], 都具有一种道德教化的功能。面对激烈的 “排佛” “辟佛” 运动, 契嵩所提倡的 “儒释一贯” 必然 有一种 “屈佛以尊儒” 的韵味, 主动寻求儒释二教的一致 性, 求大同存小异, 在根本价值导向上两者都是劝人向善, 在维护社会稳定上两者也都是奉行王道。除此之外, 契嵩 还常常在书中引用儒家圣人的经典, 这必然加深了佛教在 传播过程中的 “儒化” 色彩, 为儒释互动调和提供了理论 基础。虽然契嵪坚持 “儒释一贯” , 但并非贬低佛教教义 不如儒家思想, 而仍主张维护佛教的教义、义理, 认为其 核心精髓不亚于儒家, 甚至高于儒家。无论是借儒家圣人 经典为佛教生存寻找依托, 还是在某些问题上弱化佛教, 使其带有儒家色彩, 却又恰到好处地维护了佛教的尊严, 契嵩的 “儒释一贯” 均符合儒家 “内圣外王”之道。

儒释的会通融合, 完全是佛教在中国社会环境下生存 发展的需要, 如何调和两者之间的矛盾关系, 是佛教本土 化的一个重要内容。“在赵宋一代倡佛儒交融的, 除智圆 外, 契嵩是另一个重要代表。契嵩在会通调和佛儒方面, 甚至比智圆走得更远，思想也比智圆具体、深刻。” [7] 契嵩在中国佛教史上的影响, 对宋代以后儒释二教甚至儒 释道三教的融合都起到很大的推动作用。他所倡导的 “儒 释一贯”, 通过盛赞儒家传统伦理思想的精华, 找到儒佛 二教的共通点, 即为 “孝”。契嵩将传统孝文化当作儒佛 二教互通的媒介, 一方面吸收儒家之 “孝” 的伦理主张, 
另一方面结合佛教的戒律教规, 最终形成了自己独特的孝 道观, 不仅大大提高了孝文化在中国传统文化中的地位, 也对当时的佛教本土化有一定的促进, 为后来禅宗的进一 步发展做出了巨大的贡献。

\section{4. “解当世儒者之訾佛” [6]}

在儒家看来: “孝悌也者, 其为仁之本与！” [1]作 为维系中国古代社会伦理关系的核心, 孝道的教化作用十 分明显, “夫孝, 德之本也, 教之所由生也。” [8]所以 作为宗教信仰的佛教也不例外, 甚至可以说 “孝” 的精髓 在佛教的地位同样不言而喻。虽然佛教规定了出家人要剃 发修行, 不能侍亲等违背儒家伦理纲常的教义, 但是在以 契嵩为主的高僧眼里, 儒佛是一致的, 佛教徒出家修行是 为了救济亲人, 普度众生, 这同样是一种 “孝” 行, 甚至 提出 “以五戒十善, 通儒之五常” 的 “大孝” 观, 而且 “孝 为戒先”。据前文笔者已指出契嵩的 “儒释一贯” 思想, 因此他的孝道观正是具有了为佛教本土化提供某种存在 的依据—— “解当世儒者之些佛”。下面笔者就《孝论》 中的孝道观的表现归纳如下:

\section{1. “以孝为本”}

契嵩在《孝本章》一文中阐述了孝道是天下大本的思 想: “夫道也者, 神用之本也; 师也者, 教诰之本也; 父 母也者, 形生之本也。是三本者, 天下之大本也。”（《孝 本章第二》) 将 “孝” 视作 “天下之大本”, 充分说明了 “孝” 在佛教中的至高地位, 也成为连接儒释互动的媒介, 甚至是佛教的根本主旨要义。可以说, 契嵩把 “孝” 这一 儒家传统伦理的核心纳入佛教教义的范畴, 正是其主张 “儒释一贯” 的表现。中国古代社会讲求宗法血缘关系, 对 “家” 和 “孝” 的观念尤其根深蒂固, 因此契嵩 “以孝 为本” 的思想正是 “中国古代最早也最突出的伦理规范” [9]的写照。“孝” 是天下大本, 是儒释二教所共同遵守 的道德规范和行为准则, 无分彼此, 并为佛教的进一步传 播奠定了理论基础。

\section{2. “孝为戒先”}

契嵩将儒家的五常与佛教的五戒进行一番对比, 提出: “夫不杀, 仁也; 不盗, 义也; 不邪滛, 礼也; 不饮酒, 智也; 不妄言, 信也。是五者修, 则成其人, 显其亲, 不 亦孝乎? 是五者有一不修, 则弃其身, 辱其亲, 不亦不孝 乎? 夫五戒, 有孝之蕴, 而世俗不睹, 忽之而未始凉也。” (《戒孝章第七》) 这种对比虽然有些牵强附会, 但仍反 映出契嵩希望佛教在儒家环境统治下有其生存的空间。佛 教的戒律如此重要, 而“夫孝也者, 大戒之所以先也”(《明 孝章第一》) , 将儒家的 “孝” 抬到了佛教戒律至上, 充 分说明了契嵩深谙其重要性, 并且符合儒家传统的“孝治” 文化。此外, 契嵩还借用释迦牟尼的亲身经历, 来印证其 观点。作为佛教的创始人, 释迦牟尼 “先以其道谕其母 氏, ……逮其丧父也, 而圣人躬与诸释, 负其棺以趋葬。” (《必孝章第五》) 作为佛教史上的一位著名高僧, 契嵩 如此重视孝道, 尊亲厚葬, 由此可见孝道在佛教中的地位
举足轻重: 不仅不排斥反而大力提倡, 承认孝道是佛教教 义戒规的根本, 两者之间并无本质上的冲突, 而且目的一 致, 即都具有道德教化的引导作用。《孝经》曾言: “夫 孝, 始于事亲, 中于事君, 终于立身。”[8]由此可见, 在儒家士人眼中, 所谓行孝不仅仅是忠君事亲, 更重要的 是形成自身完备的人格, 也就是人们常说的 “修身” , 即 奉行 “五常”, 如此方可为后世典范。而在佛教戒律看来, 最终修行者必须达到 “诸恶莫作, 众善奉行, 自净其意”, 而这正需要 “五戒” 的规范, 才能成就其涅槃, 完成 “立 身”之道。儒家与佛教虽然内容不一, 道路不一, 目的却 殊途同归一一惩恶扬善。从这里可以看出契嵩的孝道观是 以人格完善和精神解脱为依归, 而儒家所提倡的 “孝” 虽 是为了巩固封建社会统治和维护伦理道德秩序, 实现 “君 子之事亲孝, 故忠可移于君” [8] 的作用, 也导致儒家盲 目 “愚孝” 的悲剧多次上演。

\section{3. “孝为善源”}

契嵩在《孝论》中多次提出 “孝” 为 “百善” 之端, 将儒家的 “孝” 与佛教的 “善” 相结合, 从而指出 “孝” 才是一切道德行为实践的源头。所谓 “圣人之道, 以善为 用; 圣人之善, 以孝为端。为善而不先其端, 无善也。” (《必孝章第五》) 通过 “孝” 与 “善” 的关系阐明了佛 教主张 “善心” 的思想。而 “善心” 也是儒家所提倡的圣 人典范, 是故 “圣人之为道也, 无所不善; 圣人之为善也, 未始遗亲。”(《必孝章第五》) 反过来, 契嵩也认为 “孝 出于善, 而人皆有善心” (《孝出章第八》) , 从另一侧 面反映了儒家与佛教的互通关系, “孝” 虽为百善之源, 却又出自于 “善” , “孝” “善” 之间的关联也成为儒释 互动的媒介, 进一步论证了佛教不仅不排斥儒家的孝道, 相反却真正身体力行地践行之。

\section{4. “显亲为孝”}

《孝论》中提出了以 “显亲”与 “辱亲” 来区分 “孝” 或 “不孝” 的标准: “是五者修, 则成其人, 显其亲, 不 亦孝乎? 是五者, 有一不修, 则弃其身, 辱其亲, 不亦不 孝乎? ” (《戒孝章第七》) “五者” 即为笔者前文提到 的儒家 “五常” 和佛教 “五戒”, 两者是对应的, “显亲” 即为光宗耀祖, 这与儒家提倡的光大门楣不谋而合, 同样 是一种 “孝”。要达到 “显亲” 的目的, 当然离不开实际 行动, 即 “孝行”。孝行的本义即谓 “养亲” , 父母养育 子女, 子女赡养父母, 这是儒家士人最最基本的德行规范。 但是, 仅仅 “养亲” 是不够的, 若想达到行孝的目的, 还 必须 “敬亲”。而所谓 “敬亲”, 必讲究一字曰 “诚”, 是以“心诚则灵”, 契嵩总结为: “诚也者, 成也。” (《原 孝章第三》) 佛教徒在修行过程中践行孝道, 以诚行孝, “其事亲也全, 其惠人恤物也均” (《原孝章第三》), 最终 “成其道也”。倘若 “行不以诚, 则其养有时而贵也”

(《原孝章第三》) , 就是说真正的 “孝” 是在 “行” 的 前面, 归根结底意味着佛教的修行离不开儒家的孝道, 而 在行孝的过程中 “必先诚其性, 而然后发诸其行也”（《原 孝章第三》), 从理论和行动上去实践, 才能最终 “显亲 为孝”。 


\section{5. “孝为至道”}

也就是说, “孝道” 是至高无上的, 是天经地义的, 与天地和鬼神同理同灵, 是为 “天地与孝同理也, 鬼神与 孝同灵也” (《原孝章第三》) 。孝道在佛教中备受推崇, 甚至提出: “孝顺至道之法。儒曰: 夫孝置之而塞乎天地, 溥之而横乎四海, 施诸后世而无朝夕。”(《原孝章第三》) 接着契嵩藉由 “孝为善源” 和 “显亲为孝” 发出 “善天下, 道为大; 显其亲, 德为优” (《孝略章第十》) 的议论, 引发出对 “道” 和 “德” 关系的思考。契嵩在《孝论》中 对此作出了解答: “道也者, 非世之所谓道也。妙神明, 出死生, 圣人之至道者也。德也者, 非世之所谓德也。备 万善, 被幽被明, 圣人之至德者也。”(《德报章第九》) 何谓之 “道”, 是一种掌握佛教真谛, 遁入生死轮回之道; 何谓之 “德”, 是泽被众生的慈悲情怀, 悟道之后的恩德。 这两者皆离不开 “孝道” 的理论教化, 这也为儒佛一致论 提供了证据。契嵩认为佛教徒为了 “成其道也” , 其一些 行为也不必拘于儒家的世俗礼法, 只要心中有孝, 重在修 身, 即为 “至道”。

\section{6. “佛教大孝”}

契嵩虽然倡导儒佛一致, 但又指出相对于儒家世俗之 “孝” 而言，佛教之 “孝” 才是为 “大孝”。这一点体现 在两个方面: 其一, 认为佛教的轮回转世, 众生 (包括神 灵) 皆为 “昔之父母精神之所来, 故戒于杀, 不使暴一微 物, 笃于怀亲。”(《评孝章第四》) 在契高看来, 一切 众生总在轮回中不断转世, “故其追父母于既往, 则逮乎 七世; 为父母虑其未然, 则逮乎更生, 虽谲然骇世, 而在 道然也。” ( 《评孝章第四》) 无论前世、今世抑或是来 世父母, 佛教均一致看待, 唯恐误杀一切众生 (佛教认为 神灵也是有情的），是此 “孝” 相比儒家世俗之 “孝” 意 义更广泛宏大, 毕竟世俗之孝 “局一世而暗于玄览, 求于 人而不求于神” , 也反映出契嵩在佛教的教义传播中眼光 更加长远, 看到过去、现在和未来, 提出 “忌戒杀” 的理 念, 是一种博爱和 “大孝” , 同时从侧面反映出他的环境 保护思想, 因为从某种程度上而言, “孝” 的范围就是包 括周边环境的。其二, 契嵩认为佛教可以 “广孝” 和 “神 孝” ，而儒家却只能 “守孝”。“是见儒而未见佛也！佛 也极焉, 以儒守之, 以佛广之, 以儒人之, 以佛神之, 孝 其至且大矣。” (《广孝章第六》) 佛教之所以提倡 “广 孝”, 正是源于其众生平等的观念, 而儒家却奉行 “亲亲 为大” 的亲疏有别。所谓儒家的仁爱思想, 是建立在 “亲 亲而仁民, 仁民而爱物” [10] 的血缘基础上, 有等级差别, 尽孝的对象只能是自己的父母和祖先。而佛教是对一切万 事万物, 包括神灵都保持着仁爱孝心， “等一物我”。佛 教的这种 “广孝”思想后来被张载吸收, 并据此提出了 “民 吾同胞, 物吾与也” [11]的主张, 将儒家的孝道推广到了 更广泛的境地。“佛教大孝” 的理念不仅体现了孝道思想 是儒佛对话中的重要一环, 更影响了儒家士人的思维, 并 将之推广开来, 儒释之间的这种相互融合充分证明了 “孝” 在中华民族精神塑造上的重要价值。

\section{7. “修法终孝”}

“父在, 观其志; 父没, 观其行。三年无改于父之道, 可谓孝也” ( 《终孝章第十二》) , 这是儒家对 “终孝” 的看法, 体现出丧制和丧仪在孝行上的重要性。儒家强调 父母之丧, 子女披麻戴孝, 守孝三年, 而这一点在契嵩看 来, 父母一殁, 僧者 “必心丧”, 此时最好的办法就是 “静 居, 修我法, 赞父母之冥。过丧期, 唯父母忌日, 孟秋之 既望, 必营斋, 讲诵如兰盆法, 是谓孝之终也。” (《终 孝章第十二》) 此外, 契嵩认为相比儒家的披麻戴孝, 佛 教徒 “服大布” 即可。由此也可以看出, 契高之所以写作 《孝论》, 正是因为“未始修法为父母之冥赞” (《孝论》), 因此佛教提倡为亡者修法超度, 为亲人尽 “终孝”。

从上述契嵩的孝道观看来，佛教对于 “孝” 的重视与 儒家无二, 甚至将 “孝” 视为伦理戒律的核心, 大大提高 了 “孝” 在中国佛教史上的重要地位, 也体现了 “夫孝, 诸教皆尊之, 而佛教殊尊也” (《孝论》) 的观点。可以 说, 传统孝文化的思想在佛教本土化和儒释互动进程中的 重要媒介作用, 也对北宋初期的 “排佛” 思潮作出了强烈 的反击。“夫孝, 天之经也, 地之义也, 民之行也” , 契 嵩的孝道观融合了儒释的精华, 契合了中国古代传统文化 的土壤, 并提出了 “解当世儒者之訾佛” 的主张, 为佛教 孝道化内涵的外延提供了理论依据。

\section{5. 孝文化与佛教儒学化的外延}

“孝” 构成了中国传统伦理道德的核心主题, “百善 孝为先”, 因此孝文化也就成了传统文化的主旋律。佛教 自从汉代传入中原后, 就经历了接受一一排斥一一再接受 的道路, 最终在中国本土找到了自己生存的空间。可以说, 佛教在进入中国后, 逐渐接受儒家伦理思想的影响后, 以 传统孝文化为媒介, 一步步在佛教教义中吸收了孝道思想, 并加以糅合, 形成了佛教的孝道观。因此从某种意义上说, 佛教孝道化的过程与佛教本土化的过程是同时进行的, 同 时也是儒释二教互动融合的过程, 最终导致佛教儒学化的 出现。从契嵩的《孝论》来看孝文化与佛教儒学化的关系, 主要体现在以下四点:

首先, 虽然契嵩认为佛教思想中蕴含了“孝”的内涵, 佛教之 “孝” 高于儒家之 “孝” ，甚至儒佛二教在 “孝” 的主张上是共通的, 但是他所主张的佛教孝道却未脱离生 活的实际, 凌驾于世之上。契嵩之所以 “屈佛以尊儒”, 对佛教孝道思想进行全新的诠释，其目的不外乎在于消除 掉儒佛二教之间的界限, 其所谓的 “儒释一贯” 最终是为 了宣扬传播佛教教义。从这个角度而言, 契嵩的佛教儒学 化 “仅仅是在理论的融通上对佛学进行了 “微调” , 使其 从形式上保持了和儒学基本观点的融洽, 并没有深入到佛 教的基本理论和修行实践, 从而实现了佛学理论的高妙和 儒化并行不悖。”[12]

其次，契嵩对儒佛二教的功能进行对比，他认为 “儒 者、佛者, 圣人之教也。其所出虽不同, 而同归乎治。儒 者, 圣人之大有为者也; 佛者, 圣人之大无为者也。有为 者以治世, 无为者以治心。”[6]儒家提倡有为治世, 佛 教倡导无为治心, 而治世与治心皆指明了世人修身立志之 
行为准则, 儒佛并行, “是不惟内有益于圣贤之道德, 亦 将外有助于国家之教化” [6], 而这一行为准则最集中的 表现就是推崇孝文化。该理论充分体现出了契高的佛学思 想有佛表儒里的倾向, 其根本意图是入世归儒契嵩这种身 兼儒释二教的个性, 对于宋代士人崇佛谈禅风气产生了很 深远的影响, “出入于佛老”, 甚至开启了佛教儒学化和 世俗的道路。

再次，契嵩的 “儒释一贯” 思想承认了儒佛二教在国 家治理中的重要作用, 是为 “同归于治” , 而且针对儒家 “排佛” 思潮而主张儒释互动, 不可避免带有儒家的深刻 烙印。从这一角度来讲, 佛教儒学化不仅推动了佛教的世 俗化, 而且刺激了儒家学者对其思想高度的进一步修改整 合, 从而促使理学的产生。可以说, 在这个环节中, 孝文 化搭起了儒释互动的桥梁, 从而催生了佛教儒学化的进程, 进而影响了佛教的世俗化, 导致儒家思想的理论深化。

最后, 契嵩强调佛教在有益于中国古代社会王道的实 现上，同儒家正统思想的目的是一致的，即 “治身心，敦 教化” (《六条诏书》) , 归根结底是为了劝人向善, 而 这又离不开孝道思想在其中的引导作用。总的来说, 契嵩 虽然迫于当时现实环节的压力, 将佛教进行儒学化的改造, 但却在字里行间处处维护了佛教的立场, 并使二者消除矛 盾融合一体, 更容易得到儒家士人的接纳, 佛教在中国古 代社会的地位愈加稳固。总而言之, 儒释互动的进程是并 行不悖的两条线: 儒学的 “佛教化” 和佛教的 “儒学化”, 两者缺一不可, 同步进行, 最终构成了佛教儒学化的外延。

\section{6. 结论}

中国古代传统社会以儒家思想为正统，而儒家正统又 以孝文化为核心, 由于社会变迁和文化的交融，导致孝文 化的传播途径也随之增多。以孝文化为纽带, 中国许多传 统文化与外来文化打破冲突, 开始对话。总而言之, “孝 在历史上虽具有局限性, 但孝顺是人的本性, 知恩报恩是 孝道的主要依据, 它具有普遍性和超越时代的特性。”[13] 因此弘扬孝道就成为中古代社会众多文化思想的主题, 佛 教也不例外。北宋的高僧契嵩身体力行, 为儒佛二教的会 通融合做出了卓越的贡献。故“律制佛子必减其衣孟之资, 以养父母也” ( 《孝行章第十一》) , 从孝道观上出发, 构建起宋代佛学的新特点, 从而缩短儒佛之间的距离, 反 过来而言, 儒释互动也为儒家学者完善思想理论体系带来 了全新的尝试。“对传统孝观念的批判继承, 也是对中国 传统文化的核心内容进一步发掘、整理、综合、分析的过 程, 目的是为了 '古为今用” 、推陈出新, 使其符合时代 的要求, 为建设中国特色的社会主义现代化事业服务。” [14]因此, 在文明冲突仍然存在的今天, 大众可以从契嵩 秉持 “儒释一贯” 的态度去看待不同文化间的共通性, 求 同存异。当今社会更是需要以孝文化为道德核心的价值观 体系塑造, 有利于在全社会推广发扬, 为当前和谐社会的
创建打下坚实的基础, 或许这正是传统孝文化所带来的启 示。

\section{参考文献}

[1] 张燕婴. 论语译注 [M]. 北京: 中华书局, 2006：2-14。

[2] 陶新宏. 宋初佛教儒学化之管窥一一以契嵩《辅教编》为例 $[J]$. 长安大学学报 (社会科学版), 2011 (3): 53-57。

[3] 刘复生. 宋仁宗时期反佛老思潮及其特点 [J]. 中州学刊, $1993(4)$ : 115-120。

［4］孙复. 孙明复先生小集 [M].《宋集珍本丛刊》第三册. 北京: 线装书局, 2004: 170。

[5] 赖永海. 慧能与中国佛教的儒学化: 林有能、霍启昌主编.六 祖慧能思想研究 [C].广州: 学术研究杂志社, 1997: 61-69。

[6] 释契嵩. 镡津文集 [M]. 《宋集珍本丛刊》第四册. 北京: 线 装书局, 2004：362-411。

[7] 赖永海. 宋元时期佛儒交融思想探微 [J]. 中华佛学学报, 1992 (5) : 109-120。

[8］胡平生. 孝经译注 [M]. 北京: 中华书局, 1996：1-31。

[9] 陈来. 古代宗教与伦理 [M]. 北京: 三联书店, 1996:300。

[10］万丽华、蓝旭. 孟子译注 [M]. 北京: 中华书局, 2006:315。

[11] 张载. 张载集 [M]. 章锡琛, 点校. 北京: 中华书局, 1978:410。

[12] 张轩. 从 《辅教编》看契嵩 “儒释一贯” 的基本理路与特点 $[J]$. 洛阳师范学院学报, 2014 (1) : 52-55。

[13] 秦海蒸. 传统孝文化的传播与外延一一以明代山东为研究 对象 $[J]$. 济南大学学报 (社会科学版), 2006 (1):63-67。

[14] 李翔. 试论中国传统孝文化的历史变迁及其价值 $[J]$. 四川 民族学院学报, 2010 (5): 48-56。

[15] 喻静. 对佛教孝道观研究的反思一一以释契嵩为例 [J]. 社 会科学论坛, $2013(2): 31-39$ 。

[16] 郑佳佳、张禹东. 论佛日契嵩的孝道观一一以《辅教篇・孝 论》为中心 $[J]$. 华侨大学学报（哲学社会科学版）, 2014(1) :69-77。

[17] 查金萍. 契嵩的“非韩”及其在宋代韩愈接受史中的意义 $[\mathrm{J}]$. 聊城大学学报（社会科学版）, 2014(6): 30-36。

[18］陈坚. “妥协论证” 与 “方便教化” ——牟子和契嵩对于儒 学的不同抉择 $[J]$. 宜春学院学报, 2015 (5) : 15-22。

[19] 郭锋航. 宋代禅僧的儒学观研究 [J]. 湖北社会科学, 2015 (10) : 115-117。 